\title{
Exploring the Difference of Chain Brand's Operation from the Perspective of Economics: Taking Disneyland as an Example
}

\author{
Ziqiao Wang, ${ }^{1, *}$ \\ ${ }^{1}$ Nanjing NO.1 High School, Nanjing, Jiangsu Province, China, 210001
*Corresponding author. Email: zqwangnj@gmail.com
}

\begin{abstract}
Based on the situation before the Covid-19, which ruled out the impact of policies of different countries, focusing on why Hong Kong Disneyland Resort (hereinafter referred to as HKDL) lose money, but Shanghai Disney Resort (hereinafter referred to as SHDL) can make a profit from the perspective of Economics and Business Management. It can be demonstrated by comparing the two resorts and utilizing knowledge of Microeconomics and Macroeconomics, like using the marginal method to analyze and accessing to different materials. From the official website, accurate information can be collected and the book of principles of economics can provide strong and professional knowledge. After researching, without the epidemic situation, people's preferences changed a lot because they have more choices. Many people choose SHDL. However, the opening of SHDL is not the direct reason that causes HKDL to lose money. The high salary and drawbacks of huge total cost are responsible for the losses. The two resorts adopt the same and different business strategies to increase their gross sales. With the epidemic situation, most Chinese tourists choose SHDL. HKDL is mainly for HK residents. However, due to the huge difference in population base, there are obvious differences in turnover between the two places.
\end{abstract}

Keywords : Disneyland, profit, elasticity, cost, business

\section{INTRODUCTION}

With the development of economic globalization and improvement of people's living standard, since 2000 more companies have established branches overseas and the popularity of traveling increased a lot. The number of domestic tourists keep increasing from 2015 to 2019 and reached 6.06 billion in 2019[1]. Disneyland, as a cultural and entertainment company with a history of nearly 100 years, has established six resorts all over the world, attracting millions of people every year. Hong Kong and Shanghai successively established the fifth and sixth paradise in the world in 2005 and 2016 respectively. However, an interesting fact deserves attention: both located in China, according to their annual report, why does HKDL lose money every year but SHDL can make a profit? Is it because Shanghai robs part of travelers or because if the differences are reflected in the different business strategies they formulate? This paper focuses on the profit and loss problems of the two resorts, the reason behind them, and respective business solutions.

\section{DEMAND AND SUPPLY}

First of all, from an economic perspective, demand and supply are important to see. The standard price of HKDL is HKD 639, which is equal to USD 82, and that of SHDL is CNY 599, which is equal to USD 92. By using US dollars as the intermediate currency, the price of HKDL is cheaper than SHDL. However, the volume of passengers of HKDL in 2015 and 2019 is 6.8 million and 6.4 million, which the number of passengers showed a downward trend, and that of SHDL in 2019 is over 10 million. The elasticity of price of SHDL's ticket 
is smaller than that of HKDL. People are loyal to SHDL. Loyals are less price sensitive than nonloyals in the choice decision. Choice elasticities are higher for nonloyals than for loyals[2]. Even though the price of SHDL increases or is more expensive than that of HKDL, the number of visitors would not decrease a lot. From the demand for both the two Disneyland, people are more willing to go to SHDL although the other one has a price advantage in tickets. We can see that tourist preferences have been changing. Psychology provides evidence of preference instability. Social psychologists, for example, have long argued that social influence is an important determinant of individual preferences[3]. There are various reasons that affect people's preference. One hypothesis is that has SHDL robbed business from HKDL? It is obvious that passenger flow is the basis of whether a resort can make a profit, stimulating consumption in the park and various demands for eating, drinking and fun. Without tourists, resort cannot earn a profit.

\section{COMPETITORS}

So, has SHDL robbed business from HKDL? In 2015, before the opining of SHDL, the whole year's revenue is HKD 5.1 billion and net loss is HKD 148 million. In 2019, after the opining of SHDL, the whole year's revenue is HKD 6 billion and net loss is HKD 105 million[4]. Losses have become a normal trend for HKDL, except 2013 and 2014, which are the only two years that HKDL earns profit. Hence, there is no direct connection between the loss of it and the opening of a new Disney resort.

\section{PRODUCTION COSTS}

Production costs variables and transaction cost variables are important[5]. Salary, as a fixed or semi-fixed cost for a company, accounts for a large part of the total cost. Different regions have different laws for citizens' minimum salary, and price level can also shift it. The high price level in Hong Kong is well known. In 2019, the Hong Kong government set up a minimum hourly wage, HKD 37.5. Do a math. Suppose that a Hong Kong resident works eight hours a day and 22days per month, and his monthly salary is HKD 6600, which is USD 848. Nevertheless, the minimum wage in Shanghai in the same period is monthly CNY 2300, which is USD 355 . We can see the huge difference in salary between Hong Kong and Shanghai. As mentioned above, we can roughly calculate the total monthly wage cost in the two resorts in order to compare the huge difference. HKDL has 7500 employees and SHDL has 12000 employees, so, take the minimum wage as an example, the monthly total cost of HKDL is USD 6.3 million, and that of SHDL is USD 4.2 million. We can see that HKDL spend more money on employees' salary even though it earns less than SHDL. However, there is no conclusive opinion about the interaction character of labor production and salary growth[6]. As a result, it is uncertain that paying more salary can elevate employees' working efficiency. Sometimes it will experience diminishing marginal product due to excess labor force. Moreover, with the help of cheap labor cost compared with abroad, SHDL has an advantage over it. For example, the minimum hourly wage in the United States is USD 15 and in Japan is JPY 1041, which is nearly USD 9. Thus, the huge cost of labor force and decreasing visitors both attribute to the loss. From the fact that HKDL experienced losses such a long time, the marginal revenue is not equal to marginal cost, which is not satisfied the profit maximization, experiencing dis-economics of scale. The inability of effectively control costs, including variable costs, such as electricity, maintenance, has become one of the noteworthy reasons

\section{BUSINESS STRATEGIES}

As one of the few world-class parks in the world, both the two resorts implement some same and different 
universal business strategies. Both the resorts promote different preferential activities, such as annual card. For example, the most expensive annual card of SHDL is CNY 3588. The equivalent annual card in HKDL is HKD 3588, which is cheaper than that in SHDL. Also, as mentioned before, the price of one-day ticket in HKDL is cheaper too. Companies should focus on "how can we perform it either better than, or at least instead of, our rivals[7]." Consequently, differentiated competition is necessary. We can see that a way of reducing prices was adopted by HKDL to attract tourists and money. However, SHDL adopt another way to earn profit-price increase. From January 2022, the price of standard ticket will increase to CNY 769. It has mentioned that the elasticity of it is small since the SH side decides to rise the price, which means that the demand is inelastic. A higher price increases total revenue. There are still many visitors going to SHDL. Catering in both the resorts is far more expensive than the outside food. A special regulation says that tourists are not allowed to bring food into the resort in 2019. So, consumption of food is a big part of the total revenue. As well, Disney Theme Hotel serves the same function. Shanghai has two theme hotels and their occupancy is up to $90 \%$ in 2016. Hong Kong has two theme hotels and their occupancy is $74 \%$ in 2019 [8]. The reason is that the area of HKDL is not very huge, which is 126 hectares, but SHDL occupied 390 hectares. Most projects in the park can be completed in one day. Visitors do not need to stay there for another day. Also, the underground between HKDL and downtown is convenient. Consequently, the occupancy rate is not as high as that in SHDL.

\section{SUPPLEMENT}

The above analysis is based on the situation before the Covid-19. under the background of Covid-19, the situation of HKDL is worse. Due to the closure of customs, mainland tourists no longer go to Hong Kong or HKDL for traveling. Overseas tourist cannot go to Hong Kong freely because segregation is required. SHDL has become the dominant resort for the Chinese.

\section{DISCUSSION}

In the future, countries in the world should stay together to control the spread of the virus and decrease the number of patients. Countries can resume tourism between them to stimulate the economy and consumption, increasing the opportunities for cultural exchanges. For example, the HK government and Singapore government plan to start "Air Tourism Bubble", which aims to promote tourism on both sides. As more people come to visit Hong Kong, it will definitely increase the revenue of HKDL. Moreover, HKDL had made a plan to extend its area to have more new different theme region to attract people. The quality of service is an advantage of it. It can also attract people in the Guangdong-Hong Kong-Macao Greater Bay Area and Southeast Asia to visit around. In order to control the total cost, the resort needs to carefully calculate the need for employees. Putting more service employees in frequently visited spots could contribute to higher and easier accessibility by visitors[9]. HKDL should reasonably arrange workers to cover the whole park, avoiding surplus or shortage of staff in specific areas. In Economics, according to the law of diminishing marginal utility, more people do not mean better. Try to find the point that MU is equal to zero.

Look at Shanghai, it seems that its prospect is more promising. Backed by the mainland's huge base of more than one billion people, there's no need to worry about the passenger flow. The challenge for SHDL is to think about how to make more money. Rising ticket price is a way that they have implemented. Increase the service quality and the taste of food in the resort's restaurant. If people can buy cheap and delicious food in the park, they will not feel so strongly about bringing food from home[10]. People are more willing to stay there. 
Reducing queue time for passengers can also increase their favorable impression to attract repeat customers. By learning from each other and active competition, the two resorts can become better in the future.

Whatever HKDL or SHDL, they give play to many influences to China, southeast Asia and the world. Combing the Chinese and Western tradition, with the help of the popularity of Internet, they boost the development of economy and propagate different areas.

\section{CONCLUSION}

Through an in-depth comparison of the characteristics of SHDL and HKDL, the demand for the former is greater than the latter one. According to their geographical location and radiation area, SHDL can cover East, North, Northeast,Central China, etc, but HKDL is more convenient for South, West China and Southeast Asia. It is worth mentioning that there is another Disneyland in Asia located in Tokyo, Japan. It diverts part of the passenger flow, which the volume of passengers in 2019 was 17 million. From the number of visitors, HKDL has no advantage and difficulties to increase revenue. However, SHDL, as a competitor, cannot be directly considered as the cause that makes HKDL lose money. Over the past two decades, most of the time is in a state of loss.

As we know, profit is equal to total revenue minus total cost. The total cost of HKDL is greater. Wages account for a large part of the cost since Hong Kong has a high price level and expensive housing price. Daily maintenance, tax rate, decoration, clothing, performance need money whatever tourists come or not.

Thus, how to make money and turn losses into profits, new and different business strategy is the key. Resorts can refer to different elasticity, deciding whether to raise or lower price. Carrying out internal improvement in the park and update theme are useful.

\section{ACKNOWLEDGMENTS}

This essay cannot be finished without the help of my kind and warm-hearted teachers, parents and friends. Here, I want to express my thanks to those people. During the periods, I learn a lot and have many words to say.

First of all, I am grateful to my respected professor Lichtenberg. Thanks to his meticulous explanation of every detail in Social Economics. He is patient and knowledgeable. He showed me a lot of cases to help me understand theories. Also, my thesis teacher provide me with a lot of help. She provides me with ideas and the correct format through repeated video calls and helps me revise my paper.

Secondly, I want to express my gratitude to my parents. Thanks to their selfless dedication and full support.

Finally, I would like to thank myself for accomplishing the paper and never giving up.

Thank you all again.

\section{REFERENCES}

[1] Website of the Ministry of Culture and Tourism. Statistical Bulletin of the Ministry of Culture and Tourism of the People's Republic of China on Cultural and Tourism Development in 2019.

[2] Lakshman Krishnamurthi and S. P. Raj. An Empirical Analysis of the Relationship between Brand and Loyalty and Consumer Price Elasticity. Marketing Science, Vol. 10, No.2(Spring 1991), pp. $172-183$

[3] Till Grune-Yanoff, Sven Ove Hansson. Preference change: Approaches from Philosophy, Economics and Psychology. Springer Science\&Business Media, 2009 
[4] Hong Kong Disneyland Website, Shanghai Disneyland Website. 2019

[5] James M. Ferris, Elizabeth Graddy. Production Costs, Transaction Costs, and Local Government Contractor Choice. Economic Inquiry 29(3), 541-554, 1991. pp.18

[6] Marina V Simonova, Lidiya P Bazhutkina, Vladimir A Berdnikov. Approaches to the System Increase in the Region on the Ground of Labor Production Growth. Canadian Center of Science and Education,pp. 7, 2015

[7] Richard P. Rumelt. Evaluating Business Strategy. ResearchGate. 1993. pp.4

[8] Hong Kong Disneyland Resort revenue reaches HK $\$ 6.0$ billion, hotel occupancy stands at $74 \%$ in FY19. China Travel News. 2020

[9] Nelson K. F. Tsang, Louisa Y. S. Lee, Alan Wong, Rita Chong. THEMEQUAL-- Adapting the SERVQUAL scale to theme park services: A case of Hong Kong Disneyland. Journal of Travel\&Tourism Marketing 29(5), 416-429, 2012.

[10] Pan Qiting, Nobuhiro Uno, Yoshiaki Kubota. Kano Model Analysis of Customer Needs and Satisfaction at the Shanghai Disneyland. Graduate School off Management, Kyoto University. 2011. pp.9 